\title{
A Comprehensive Review on the Diabetic Retinopathy, Glaucoma and Strabismus Detection Techniques Based on Machine Learning and Deep Learning
}

\author{
Md. Muntasir Kamal ${ }^{1}$, Md. Hachibul Islam Shanto ${ }^{1}$, Mirza Mahmud Hossan ${ }^{1}$, Md. Abul Hasnat ${ }^{1}$, \\ Sharmin Sultana ${ }^{1}$, and Milon Biswas ${ }^{1}$ \\ ${ }^{1}$ Department of Computer Science Engineering, Bangladesh University of Business and Technology, Dhaka, Bangladesh. \\ *Corresponding author: muntasir3217@gmail.com (Md. Muntasir Kamal, Department of Computer Science Engineering, \\ Bangladesh University of Business and Technology, Dhaka, Bangladesh).
}

\begin{abstract}
Diabetes is a condition in which a person's body either does not respond to insulin supplied by their pancreas or does not create enough insulin. Diabetics are at a higher chance and risk of acquiring a variety of eye disorders over time. Early identification of eye diseases via an automated method has significant advantages over manual detection thanks to developments in machine learning techniques. Recently, some high research articles on the identification of eye diseases have been published. This paper will present a comprehensive survey of automated eye diseases detection systems which are Strabismus, Glaucoma, and Diabetic Retinopathy from a variety of perspectives, including (1) datasets that are available, (2) techniques of image preprocessing, and (3) deep learning models. The study offers a thorough overview of eye disease detection methods, including cutting-edge field methods, intending to provide vital insight into the research communities, all eye-related healthcare occupational, and diabetic patients.
\end{abstract}

Keywords: Strabismus, Glaucoma, Diabetic retinopathy, Convolutional neural network, and Deep learning.

\section{INTRODUCTION:}

Eye diseases comprise a group of eye disease combinations that includes Diabetic Retinopathy, Strabismus, Glaucoma, etc (Valverde et al., 2019). All types of eye diseases are harmful to human beings. For affecting eye diseases there occurs blindness and loss of vision from 20-74 ages. According to WHO, around 2.2 Billion people are affected by different types of eye diseases. In this article, we will discuss DR, GL, and Strabismus. Diabetic Retinopathy is an eye disease. Damage to the bloodstream of the light-sensitive tissues at the optic nerve causes DR. In the backside of the eye, this retina is indeed a sensitive layer of the eye that converts lights into electric signals.

UniversePG I www.universepg.com
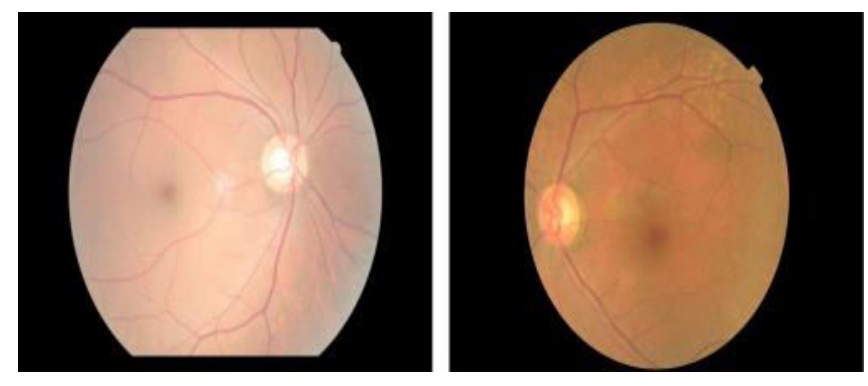

Fig. 1: Normal eyes fundus images.

In the backside of the eye, this retina is indeed a sensitive layer of the eye that converts lights into electric signals. To see the visual object, the brain decodes the electric signal. The retina needs a supply of blood constantly, which it receives through a tiny blood vessels network. 
The major two stages of DR include - (i) Early DR, (ii) Advanced DR. Early DR is generally known as NPDR (non-proliferative diabetic retinopathy). In the early stage of DR, the retina's blood vessel walls are weakened. From the vessel walls, the Wendy lumps are protruded, occasionally leaking blood and fluid into the retina. Tissues inside the retina may expand, conducting white spots inside the retina. On the other hand, advanced DR is said PDR (proliferative diabetic retinopathy). In advanced DR, the damaged blood vessels prick the crystalline jelly that fills the center of the eye causing the improvement of odd blood vessels inside the retina. The pressure can increase in the orb because recently produced blood vessels break the normal flow of the fluid. This can damage the optic disk or nerve which carries images from the eye to the brain. The effects of DR are - gradually worsening vision, blurred vision, sudden vision loss eye pain or redness, etc (Azam et al., 2020).
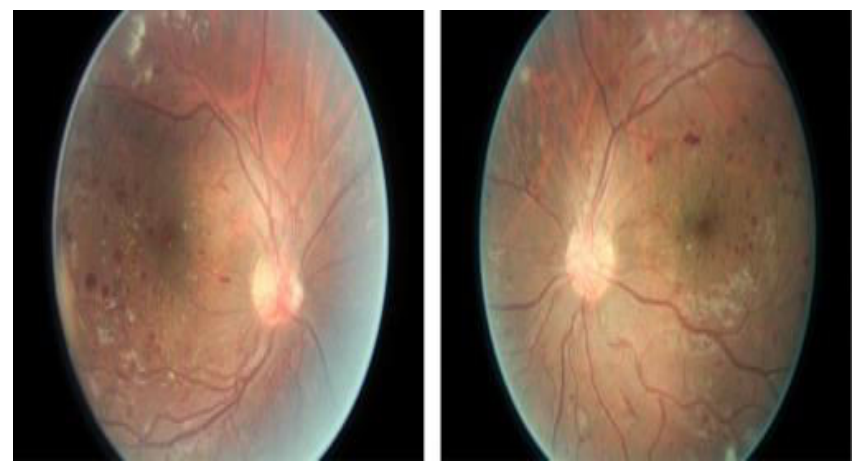

Fig. 2: Diabetic Retinopathy.

Another eye disease is Glaucoma. It's a condition of eye disease where the optic nerve is damaged. The nerve links the eyes to the human brain. When the eye's intraocular levels are high, the optic nerve suffers, It's the purpose for affecting glaucoma. The main sign of GL is a visual impairment.One of the most common causes of blindness is GL. The signs and symptoms of glaucoma are - (i) intense eye pain (ii) redeye, (iii) nausea and vomiting, (iv) a headache, (v) tenderness around the eyes, (vi) seeing rings around lights, (vii) blurred vision, etc. There are mainly two types of GL. They are - (i) open-angle (ii) angle-closure.
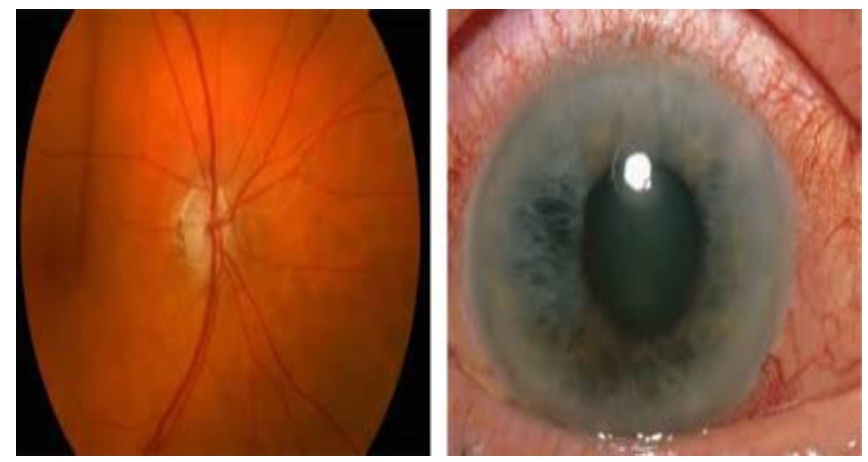

Fig. 3: Glaucoma.

Strabismus is another eye diseases condition where the eyes are not lined up with one another. In other words, we can say, one eye is turned in a direction that is completely different from another eye. In normal eye conditions, the six muscles control eye movement and point both eyes together (Khaleduzzaman et al., 2021).

The problem in the functioning of these muscles or in the nerves that control these muscles is thought to be the cause of strabismus. The strabismus-affected patients can't control eye movement and can't keep normal ocular alignment. The most common signs and symptoms of strabismus are - (i) Double vision, (ii) Blurry vision, (iii) Difficulty in reading, (iv) Loss of depth perception, (v) weakness around the eyes. There are 4 categories strabismus which are - (i) esotropia, (ii) exotropia, (iii) hypertropia, (iv) hypotropia.
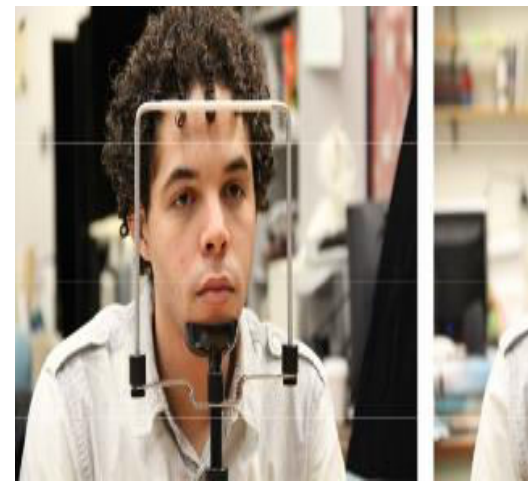

UniversePG I www.universepg.com 


\section{METHODOLOGY:}

A well-organized selection is used to do research. First of all, we targeted a survey then we selected keywordbased papers on related work. After that we did a critical review of selected articles then the observation and discussion process is done on the articles. Finally, the conclusion is done. The below flowchart shows the research procedure.

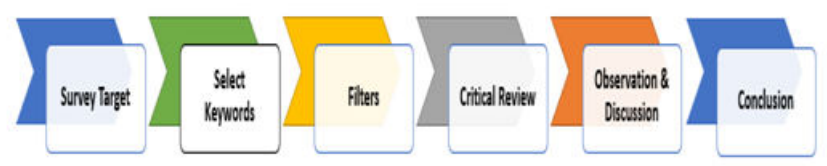

Fig. 5: Diagram of our research method.

\section{Selection of Articles:}

We collected articles from 8 different databases considering our review target. The 8 databases are - (i)
IEEE Explore (ii) Science Direct (iii) DeepAI (iv) Springer (v) Academia (vi) SSRN (vii) Hindawi (viii) ACM. From them, we applied seven filtering methods to select our primary review target. The first filtering process is done for ML, DL, TL, image processing, image classification, diabetic retinal disease, diabetic eye disease, DR, GL, and Strabismus keywords. The second filtering method refers to the articles published from the year 2016 to 2021 . The third filtering method is based on conferences and journals. To remove duplicate articles, we used the fourth filtering method. The fifth filtering method is based on articles title, abstract, introduction, and conclusion. The sixth filtering method is done by scanning references and citations. The final filtering method is quality assessment. The filtering method is shown in the figure below:

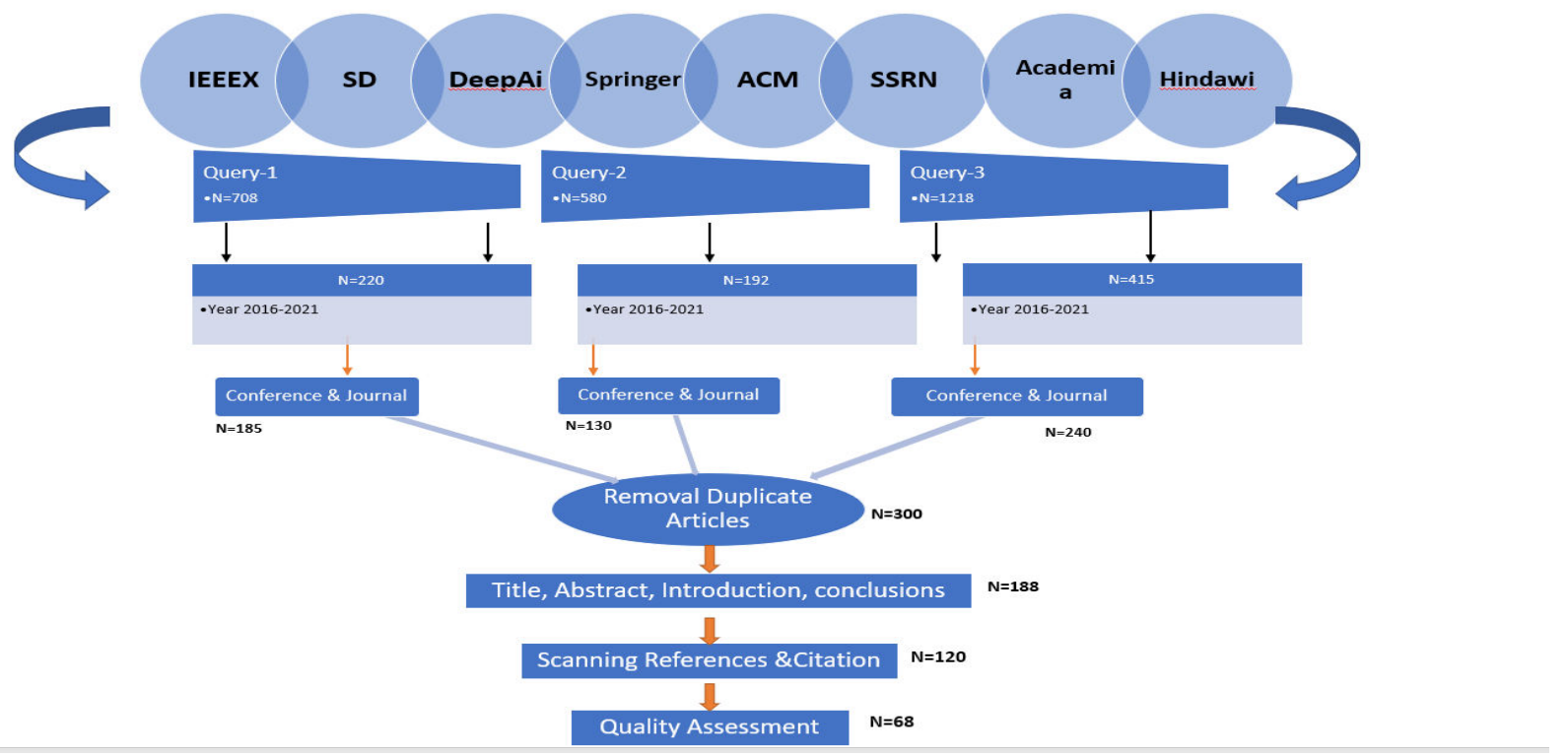

Fig. 6: Selection process of our articles.

\section{Eye Diseases Data Sets}

The articles we have selected, In those articles, the authors used public and private datasets. The datasets are from Cave, Kaggle, Eye Disease Dataset, Siblings DB, and Messidor (Zolkifli et al., 2021), (Decencière et al., 2014), (Jain, 2018; Almeida et al., 2012). They are used for sample image data for training and testing. Authors (Zolkifli et al., 2021) used Cave, Kaggle, Eye Disease Dataset, and SiblingsDB used for sample image data for research. Authors in (Gondal et al., 2017; Gulshan et al., 2016; Quellec et al., 2017, Roy et al., 2017; Li et al., 2017; Grinsven et al., 2016; Sayres et al., 2019; Doshi et al., 2016; Gargeya et al., 2017; UniversePG I www.universepg.com
Jiang et al., 2017; Hajabdollahi et al., 2019; Bir et al., 2020; Yang et al., 2017; Torre et al., 2020; Torre et al., 2020; Sisodia et al., 2017) used Kaggle dataset and (Li et al., 2017; Van Grinsven et al., 2016; Umapathy et al., 2019; Abbas et al., 2017; Orlando et al., 2018; Bahrami et al., 2018; ZOLKIFLI et al., 2021) used the dataset from Messidor (Decencière et al., 2014). There are 88,702 images in the Kaggle dataset. In that, about 35,126 and 53,576 images are used for training and testing purposes. There are 1200 fundus images in Messidor (Decencière et al., 2014), which is the most widely used dataset. The below Table shows information of selected articles datasets - 
Table 1: Short form of various terms.

\begin{tabular}{|c|c|}
\hline Full form & Short-form \\
\hline Diabetic Retinopathy & DR \\
\hline Glaucoma & GL \\
\hline Deep Learning & DL \\
\hline Machine Learning & ML \\
\hline Transfer learning & TL \\
\hline Convolutional neural network & CNN \\
\hline proliferative diabetic retinopathy & PDR \\
\hline Random Forest & RF \\
\hline Support Vector Machine & SVM \\
\hline Backpropagation Neural Network & BPNN \\
\hline Gaussian Filter & GF \\
\hline Illumination Correction & IC \\
\hline Image Rotation & IR \\
\hline
\end{tabular}

\begin{tabular}{|c|c|}
\hline Blood Vessel Segmentation & BVS \\
\hline Grayscale Conversion & GSC \\
\hline Augmentation & $\mathrm{Au}$ \\
\hline Resize & $\mathrm{Re}$ \\
\hline Contrast Enhancement & $\mathrm{CE}$ \\
\hline $\begin{array}{c}\text { Contrast Limited Adaptive } \\
\text { Histogram Equalization }\end{array}$ & CLAHE \\
\hline Region of Interest & ROI \\
\hline Histogram Equalization & HE \\
\hline Green Channel Extraction & GCE \\
\hline Optical coherence tomography & OCT \\
\hline Cross-validation & CV \\
\hline Medical image analysis group & MIAG \\
\hline $\begin{array}{c}\text { Prevalence and Bias-Adjusted } \\
\text { Fleiss' Kappa }\end{array}$ & PABAK \\
\hline Diabetic Eye Disease & DED \\
\hline
\end{tabular}

Table 2: DR, GL, Strabismus datasets description.

\begin{tabular}{|c|c|c|c|}
\hline $\begin{array}{c}\text { Eye } \\
\text { Disease }\end{array}$ & Dataset & Description & References \\
\hline \multirow[t]{4}{*}{ DR } & Messidor & $\begin{array}{l}\text { The dataset has } 1200 \text { fundus images. Among } \\
\text { the } 1200 \text { images, } 800 \text { and } 400 \text { are with and } \\
\text { without pupil dilation. }\end{array}$ & $\begin{array}{c}\text { (Li } \text { et al., 2017; Grinsven } \text { et al., 2016; Abbas } \\
\text { et al., 2017; Orlando } \text { et al., 2018; Bahrami } \\
\text { et al., 2018) }\end{array}$ \\
\hline & Kaggle & $\begin{array}{l}\text { The dataset consists of } 88702 \text { images where } \\
35126 \text { and } 53576 \text { images were used for training } \\
\text { and testing. }\end{array}$ & $\begin{array}{l}\text { (Zolkifli } \text { et al., 2021; Gondal } \text { et al., 2017; } \\
\text { Gulshan } \text { et al., 2016; Vaghefi et al., 2020; } \\
\text { Quellec } \text { et al., 2017; Roy et al., 2017; Li } \text { et } \\
\text { al., 2017; Grinsven et al., 2016; Sayres } \text { et al., } \\
\text { 2019; Doshi } \text { et al., 2016; Gargeya, } \text { et al., } \\
\text { 2017; Jiang } \text { et al., 2017; Hajabdollahi } \text { et al., } \\
\text { 2019; Bir } \text { et al., 2020; Yang } \text { et al., 2017; Jain } \\
\text { et al., 2018; Almeida } \text { et al., 2012; Torre } \text { et } \\
\text { al., 2020; Torre } \text { et al., 2020; Sisodia } \text { et al., } \\
\text { 2017) }\end{array}$ \\
\hline & \begin{tabular}{|c|} 
Friedrich- \\
Alexander \\
University machine \\
learning data
\end{tabular} & $\begin{array}{c}\text { There are } 522 \text { healthy and } 1021 \text { diseased } \\
\text { images. The images were increased then to get } \\
1680 \text { images. There were about } 960 \text { and } 720 \\
\text { diseased and healthy images. }\end{array}$ & (Jain et al., 2018) \\
\hline & Deep DR & $\begin{array}{c}\text { For the classification of DR, In the dataset } \\
\text { consists of } 2696 \text { pictureswhich are from } 748 \\
\text { patients. }\end{array}$ & (Zhang et al., 2019) \\
\hline GL & RIGA & $\begin{array}{c}\text { There are three different sources in the dataset. } \\
\text { Bin Rushed (There are } 195 \text { original images in } \\
\text { the dataset those are marked by different six } \\
\text { ophthalmologists total about } 1365 \text { images). } \\
\text { MESSIDOR (The dataset contains } 460 \text { original } \\
\text { photographs. Which are manually defined by six } \\
\text { different ophthalmologists total of about } 3220 \\
\text { images). Magrabi Eye Center (There are } 95 \\
\text { original images in the dataset those are marked } \\
\text { by different six ophthalmologists total about } \\
665 \text { images) }\end{array}$ & (Al Ghamdi et al., 2019) \\
\hline
\end{tabular}




\begin{tabular}{|c|c|c|c|}
\hline \multirow[t]{5}{*}{$\begin{array}{c}\text { Strabis } \\
\text { mus }\end{array}$} & $\begin{array}{c}\text { The tele strabismus } \\
\text { dataset }\end{array}$ & $\begin{array}{l}\text { In the dataset, there are } 5685 \text { images. For } \\
\text { training purposes, } 3409 \text { images are used and for } \\
\text { testing purposes, } 2276 \text { images are used. Among } \\
\text { the training dataset, there are } 2708 \text { normal } \\
\text { images and } 701 \text { strabismus images. On the other } \\
\text { hand, the test dataset is consists of } 1806 \text { normal } \\
\text { and } 470 \text { strabismus images. }\end{array}$ & (Al Ghamdi et al., 2019) \\
\hline & CAVE & $\begin{array}{l}\text { There are } 5880 \text { images in the CAVE dataset. } \\
\text { They are } 56 \text { different subjects ranging from } 18- \\
36 \text { years old people. Among them } 32 \text { are males } \\
\text { and } 24 \text { are females. }\end{array}$ & (Zolkifli et al., 2021) \\
\hline & Siblings DB & $\begin{array}{l}\text { In the dataset, there exist } 184(92 \text { siblings pair) } \\
\text { images of their anterior, profile, vacant, and } \\
\text { chuckling faces. Among them profile images are } \\
79 \text { pairs and } 56 \text { images are of have chuckling } \\
\text { vacant and profile pictures. }\end{array}$ & (Zolkifli et al., 2021) \\
\hline & $\begin{array}{c}\text { Eye disease } \\
\text { dataset }\end{array}$ & $\begin{array}{l}\text { The Eye disease dataset is gained from Kaggle. } \\
\text { There are } 88702 \text { images in the dataset. Where } \\
35126 \text { and } 53576 \text { images were used for training } \\
\text { and testing. }\end{array}$ & (Zolkifli et al., 2021) \\
\hline & $\begin{array}{l}\text { Private Strabismus } \\
\text { dataset from opht- } \\
\text { halmological office } \\
\text { in Saint Louis }\end{array}$ & $\begin{array}{l}\text { The dataset consists of } 45 \text { patient images. Five } \\
\text { images from each patient and are divided into } \\
\text { two classes strabismus and normal. Total } 225 \\
\text { images in the dataset. }\end{array}$ & (de Oliveira Simoes et al., 2019) \\
\hline
\end{tabular}

Image Preprocessin Techniques Used in Selected Articles

There are various image processing methods and techniques to visualize the images. For increasing the visualization of the images, the images are subjected to some pre-processing steps. When the images are more clear and bright then a network can gist more supreme features. In this section, we will discuss a brief statement about the techniques of image processing that are used by the authors and researchers. On the RGB color space, the Green channel provides better contrast and information compared to the other channels (Simon, 2019). Green channel separation extraction is appointed in most image pre-processing techniques (Simon, 2019). Contrast enhancement is another very known image processing technique. Its application raises the contrast on green channel images. To raise the image, contrast enhancement is devoted to the green channel. Usually, Revelation correctness is completed to raise the brightness and intensity of light of the image after contrast enhancement.The Gaussian filter method is used to smooth out the pictures. Gaussian filter is a noise removal filter. Another well-known method of image processing is image resizing. As an example, UniversePG I www.universepg.com the resizing methodology starts with image acquisition. It is done by the re-dimensioning of the original image from $2048 * 1536$ to $205 * 154$ pixels, where the original resolution is greater than 10 times the re-dimensional resolution (Almeida et al., 2012).

The main objective of resizing is to minimize the computational cost of image processing. Feature extraction is a section of the dimensionality shortening procedure. In which, a set of strong data is separated and attenuated to major manageable groups. So, when you're ready to process it, it'll be a lot easier. If you have a large quantity of data, feature extraction comes in handy. Feature extraction reduces the amount of duplicated data in a data source. Image segmentation is the method of partitioning different image parts from the eye like the inner and outer portion of the eye, retina part of the eye, pupil diameter (Gupta et al., 2014), eyelid, sclera, eyelashes, eyelid, and take asides all impertinent niceties to improve the efficiency. Irises are typically depicted as circles of inner and outer boundaries. These two circles should not be co-centric in most cases (Umesh et al., 2016). The Table shows the image processing techniques in selected articles. 
Table 3: Image processing techniques in selected articles.

\begin{tabular}{|c|c|c|c|c|c|c|c|c|c|c|c|c|}
\hline Reference & GF & IC & IR & BVS & GSC & Au & Re & CE & CLAHE & ROI & HE & GEC \\
\hline (Li et al., 2017) & $X$ & $X$ & $X$ & $X$ & $X$ & $\checkmark$ & $\checkmark$ & $X$ & $\checkmark$ & $\checkmark$ & $X$ & $\checkmark$ \\
\hline $\begin{array}{c}\text { (Abbas } \text { et al., 2017), } \\
\text { (Diaz-Pinto } \text { et al., 2019) }\end{array}$ & $X$ & $X$ & $X$ & $X$ & $X$ & $X$ & $X$ & $X$ & $X$ & $\checkmark$ & $X$ & $X$ \\
\hline (Orlando et al., 2018) & $X$ & $\checkmark$ & $X$ & $\checkmark$ & $X$ & $X$ & $X$ & $X$ & $X$ & $\checkmark$ & $X$ & $\checkmark$ \\
\hline (Bahrami et al., 2018) & $X$ & $X$ & $X$ & $X$ & $X$ & $X$ & $X$ & $X$ & $X$ & $\checkmark$ & $X$ & $X$ \\
\hline (Vaghefi et al., 2020) & $\checkmark$ & $X$ & $X$ & $X$ & $X$ & $X$ & $\checkmark$ & $X$ & $X$ & $\checkmark$ & $X$ & $X$ \\
\hline (Quellec et al., 2017) & $\checkmark$ & $X$ & $X$ & $X$ & $X$ & $\checkmark$ & $\checkmark$ & $X$ & $X$ & $X$ & $X$ & $X$ \\
\hline (Van Grinsven et al., 2016) & $\checkmark$ & $X$ & $X$ & $X$ & $X$ & $\checkmark$ & $\checkmark$ & $\checkmark$ & $X$ & $X$ & $X$ & $X$ \\
\hline (Gargeya et al., 2017) & $X$ & $X$ & $X$ & $X$ & $X$ & $\checkmark$ & $\checkmark$ & $X$ & $X$ & $X$ & $X$ & $X$ \\
\hline (Jiang et al., 2017) & $X$ & $X$ & $X$ & $X$ & $X$ & $X$ & $\checkmark$ & $X$ & $X$ & $X$ & $\checkmark$ & $X$ \\
\hline (Yang et al., 2017) & $X$ & $X$ & $X$ & $X$ & $X$ & $X$ & $\checkmark$ & $X$ & $\checkmark$ & $\checkmark$ & $X$ & $X$ \\
\hline (de La Torre et al., 2020) & $X$ & $X$ & $X$ & $X$ & $X$ & $\checkmark$ & $X$ & $\checkmark$ & $X$ & $X$ & $\checkmark$ & $X$ \\
\hline (Gargeya et al., 2017) & $X$ & $X$ & $X$ & $X$ & $X$ & $\checkmark$ & $\checkmark$ & $X$ & $X$ & $X$ & $X$ & $X$ \\
\hline
\end{tabular}

\section{Eye Diseases Classifiction Techniques}

Here, we will investigate the approaches which are Deep Learning-based for Eye diseases detection. In Deep Learning architecture the word "deep" mentions the depth of the layers. The classification processes are :

1) The annotated dataset is divided into training and testing data for DL architecture,

2) For quality enhancement, the dataset is by the use of image preprocessing techniques.

3) For features extraction and posterior classifications, the preprocess images are compiled into DL architecture.

Here previous layer output is used as input for the current layer in DL architecture and the previous layer output is processed and passed into the following layer. From the DL algorithm, many researchers used subsisting hyperparameters like CNN or VGG-16. The algorithms are used for improving classification accuracy.

Table 4: Hyperparameter observation.

\begin{tabular}{|c|c|c|c|c|c|c|}
\hline References & Model & Image Size & Mini Batch Size & Epoch & Optimizers & Initial Learning Rate \\
\hline (Quellec et al., 2017) & o_O & $448 * 448$ & 36 & - & Adam & $1 \times 10^{\wedge}-4$ \\
\hline (Gondal et al., 2017) & o_O & $512 * 512$ & - & 150 & Adam & $1 \times 10^{\wedge}-2$ \\
\hline (Phan et al., 2019) & ResNet152 & $512 * 512$, & - & - & - & - \\
& DenseNet201,VGG19 & $256 * 256$ & & & & \\
\hline (Sayres et al., 2019) & InceptionV4 & $779 * 779$ & - & - & - & - \\
\hline (Sharma et al., 2020) & CNN & $256 * 256$ & 15 & 200 & Adam & $1 \times 10^{\wedge}-5$ \\
\hline (Li et al., 2017$)$ & AlexNet & $512 * 512$ & - & 130 & - & $1 \times 10^{\wedge}-2$ \\
\hline
\end{tabular}

Dlapproa Ches for Emplying TL, New Network, and Combined DL ML

On the primary task, TL is used for the reuse of features that is learned by DL models and its adaptation to the secondary task. When the Neural Network Architecture is trained, TL is used to minimize the computational cost. In some events, to train a Neural Network when there is not enough data then the TL is beneficial. The arguments are launched from the former learning instead of random propagation. The primary layers become acquainted with gist the fundamental features like textures, edges, and so forth whereas the peak layers are earmarked more such as exudates and blood vessels. Consequently, inimage recognition applications TL is commonly adopted as initial features gifted are shared mindless to the task. From our all studies, some researchers propounded an aggregation of ML and DL classifiers.Based onarchitecturesthe researchers used RF, SVM, and BPNN for detecting eye diseases. In this Table, Hyperparameter observed in selected articles are given - 


\begin{tabular}{|c|c|c|c|c|c|c|}
\hline $\begin{array}{c}\text { (Van Grinsven et al., } \\
\text { 2016) }\end{array}$ & OxfordNet & $41 * 41$ & 256 & 60 & - & $1 \times 10^{\wedge}-5$ \\
\hline (Asaoka et al., 2019) & ResNet & $224 * 224$ & 64 & - & SGD & $1 \times 10^{\wedge}-3$ \\
\hline $\begin{array}{c}\text { (Diaz-Pintoet } \text { et al., } \\
\text { 2019) }\end{array}$ & VGG16, VGG19 & $\begin{array}{l}224 * 224, \\
299 * 299\end{array}$ & 8 & 100 & SGD & $1 \times 10^{\wedge}-4$ \\
\hline $\begin{array}{c}\text { (Gómez-Valverde } \text { et al., } \\
\text { 2019) }\end{array}$ & $\begin{array}{l}\text { VGG19, RESNET50 } \\
\text { GoogLeNet, DENET, } \\
\text { Standard CNN }\end{array}$ & $\begin{array}{l}231 * 231 \\
231 * 231\end{array}$ & 32,64 & $\begin{array}{c}100 \\
80 ; 25 \\
50\end{array}$ & SGD & $1 \times 10^{\wedge}-4$ \\
\hline (Ahn et al., 2018) & InceptionV3 & $224 * 224$ & - & 14 & $\begin{array}{l}\text { Gradient } \\
\text { Descent }\end{array}$ & $1 \times 10^{\wedge}-5$ \\
\hline (Sahlsten et al., 2019) & InceptionV3 & $2095 * 2095$ & 15 & - & - & - \\
\hline (Jiang et al., 2017) & $\mathrm{CNN}$ & $224 * 224$ & - & 600 & - & $1 \times 10^{\wedge}-2$ \\
\hline (Torre et al., 2020) & $\mathrm{CNN}$ & $128 * 128$ & - & $\begin{array}{c}250 \\
150 ; 70\end{array}$ & Adam & $\begin{array}{c}1 \times 10^{\wedge}-3,1 \times 10^{\wedge} \\
-4,1 \times 10^{\wedge}-5\end{array}$ \\
\hline (Torre et al., 2020) & $\mathrm{CNN}$ & $512 * 512$ & 15 & 300 & Adam & $3 \times\left(1 \times 10^{\wedge}-4\right)$ \\
\hline (Hemanth et al., 2020) & $\mathrm{CNN}$ & $64 * 64$ & - & 20 & Adam & $1 \times 10^{\wedge}-5$ \\
\hline $\begin{array}{c}\text { (Raghavendra et al., } \\
\text { 2018) }\end{array}$ & $\mathrm{CNN}$ & $256 * 256$ & - & 100 & - & $\begin{array}{c}1 \times 10^{\wedge}-2 ; 1 \times 10^{\wedge}- \\
3 ; 1 \times 10^{\wedge}-4\end{array}$ \\
\hline (Ramasamy et al., 2021) & NNET & $224 * 224$ & - & - & - & - \\
\hline (Zolkifli et al., 2021) & R2018b & $\begin{array}{l}5184 * 3456 \\
\text { for cave. } \\
4526 * 283 \text { for } \\
\text { Siblings DB }\end{array}$ & - & - & - & - \\
\hline (Figueiredo et al., 2021) & ResNet50 & & & 150 & & \\
\hline
\end{tabular}

\section{DR}

DR is a kind of retinopathy caused by diabetes. DR is the subject of numerous research papers. The system employed in (Tufail et al., 2017), is Retinal pictures were manually graded using three ARIAS: iGradingM, Ret marker, and Eye Art, and processed using a standard national approach for DR screening. A reading center was resorted to for arbitration when ARIAS scores differed from manual grading. The screening performance (sensitivity, false-positive rate) and diagnostic accuracy ( 95 percent confidence intervals of screening-performance parameters) were determined in the research publication (Tufail et al., 2017). The cost per appropriate screening outcome was calculated using economic analysis. The following are the ARIAS sensitivity point estimates (95\% confidence intervals) as a consequence of the experiment: Eye Art $94.7 \%$ (94.2\% e95.2\% ) for any retinopathy, $93.8 \%(92.9 \%$ e94.6 \% ) for referable retinopathy (human graded as ungradable, maculopathy or proliferative), and $99.6 \%$ (97.0 \% e99.9 \% ) for proliferative retinopathy; Ret marker $73.0 \%(72.0 \%$ e $74.0 \%)$ for all photos were assessed as having illness or being ungradable by iGradingM. The method was validated using 400 ret-

UniversePG I www.universepg.com inal fundus pictures from the MESSIDOR database, yielding average values of $97 \%$ accuracy, $94 \%$ sensitivity (recall), $98 \%$ specificity, $94 \%$ precision, $94 \%$ F Score, and $95 \%$ t GMean for various performance evaluation metrics.

The suggested work (Saranya et al., 2020) focuses on establishing a computer-aided diagnosis tool to detect and classify DR in its early stages, as well as employing Convolution Neural Net-works to grade nonproliferative DR from retinal fundus pictures $(\mathrm{CNN})$. The methodology that is being suggested Upsampling or downsampling the data, optic disc segmentation, pre-processing images to make them model ready, and feeding pre-processed images to the CNN model for severity grading are the four stages involved. The method's limits are found in the photographs that are fed, as the categorization is heavily dependent on the quality of the images pro-vided. They achieved a result of $96 \%$ sensitivity and $91 \%$ accuracy. (Kumar et al., 2020) reported an automated early DR diagnosis technique based on improved blood vessel and optic disc segmentation strategies. This study focused on red lesion features such as microaneurysms and hemorrhages to detect the early stages of DR using the DIA- 
RETDB1 database. This enhanced model has a sensitivity of $87 \%$ and a specificity of $93 \%$. They present a DR model employing red lesion localization and a Convolution CNN classifier in this paper (Zago et al., 2020). This model was developed using DIARETDB1 datasets and tested against a variety of databases, including MESSIDOR, it achieved 91\% accuracy and 94\% sensitivity. The disadvantage is that only red lesion features were eva-luated for DR checking, and brilliant lesions were not taken into account.

\section{GL}

There is a good amount of research about GL. The researchers employed ResNet architecture then examined two datasets from different institutions (Asaoka et al., 2019). To boost the data volume, they used the data augmentation approach, and the area under the receiver operating characteristic curve was used to discover their accuracy (AROC). Therefore, they obtained two outcomes: $94.8 \%$ AROC in a supplemented dataset and $99.7 \%$ AROC in a dataset without aug-mentation. Using color fundus pictures and TL, they identified Optical coherence tomography in three dimensions (OCT) and GL in (An et al., 2019). The model AUC was evaluated tenfold using cross-validation (CV). When five different CNN models were coupled with Random Forest, the CV AUC increased tenfold to $96.3 \%$. In (Diaz-Pinto et al., 2019), five publicly available datasets were used by the researchers. They achieved a result in the sensitivity of $93.46 \%$, specificity of $85.80 \%$, AUC of $96.05 \%$. In (Lu et al., 2019), researchers classified glaucoma and non-glaucoma using the VGG network. Three separate ophthalmology centers in China provided them with VF samples. They got $82.6 \%$ specificity, $87.6 \%$ accuracy, and 93.2 percent sensitivity. In (Al Ghamdi et al., 2019) they used Semi-supervised and Supervised met-hods and achieved accuracy $92.4 \%$, sensitivity $91.7 \%$, and specificity of $93.3 \%$ in Semi-supervised. In Super-vised accuracy $81.25 \%$, sensitivity $74.2 \%$, and speci-ficity $86.3 \%$.

In (Alghamdi et al., 2021) provide a frame-work for automatically diagnosing GL that is based on three CNN models with distinct learning app-roaches in this research. They employed both labeled and un-labeled data to apply transfer and semi-super-vised learning methods. To begin, the transfer learning model starts with a pre-trained $\mathrm{CNN}$ model that has been fine-tuned UniversePG I www.universepg.com using non-medical data. Second, a semi-supervised framework based on two different unsupervised approaches was trained and constructed utilizing labeled and unlabeled data. TCNN, SSCNN, and SSCNNDAE are three models. They conducted trials utilizing two publicly available datasets, RIM-ONE and RIGA, to evaluate the GL diagnostic performance of their proposed CNN models. When comparing the classification accuracy of the various models of deep learning, it was observed that semi-supervised learning models outperformed transfer learning techniques. The SSCNN-DAE model had the greatest results, with an accuracy of $93.8 \%$, a sensitivity of $98.9 \%$, and a specificity of $90.5 \%$. (Gulshan et al., 2016) in author by handcrafting feature-based seg-mentation in retinal pictures, an automatic computer-aided diagnostics (CADx) framework is constructed for diagnosing GL eye condition. It is proposed that Deep Learning and DBN (deep-belief network) be used to automate the detection of glaucoma. The four steps of the deep belief technique are (i) automatic detection, (ii) feature extraction, (iii) feature optimization, and (iv) classification. On average, the trial findings showed an accuracy of $98 \%$, sensitivity of $83 \%$, specificity of 97 percent, precision of $84 \%$, and recall of $86 \%$. Based on three-dimensional optical coherence tomography (OCT) data and color fundus pictures, this (An et al., 2019) study attempted to build a machine learningbased method for GL diagnosis in open-angle GL patients. This study included 208 glaucomatous and 149 healthy eyes. A segmentation algorithm was used to create thickness and deviation maps. CNN transfer learning was also applied. Data augmentation is used to train $\mathrm{CNN}$. A random forest (RF) was trained to classify the disc fundus images. The models were evaluated using 10-fold cross-vali-dation (CV). Color fundus pictures had a 10-fold CV Area Under Curve of 0.940, RNFL thickness maps had a 10-fold CV Area Under Curve of 0.942, macular GCC thickness maps had a 10-fold CV Area Under Curve of 0.944, disc RNFL deviation maps had a 10-fold CV Area Under Curve of 0.949, and macular GCC deviation maps had a 10-fold CV Area Under Curve of 0.952. The 10-fold CV AUC was increased to 0.963 by RF merging the five different CNN models. At full, half, and quarter frequency scales, this study (Chaudhary et al., 2021) proposes order zero and order one 2D-FBSE-EWT algorithm. Decomposition of a fundus image into rele- 
vant sub-images is accomplished using these methods. Two approaches are employed to detect glaucoma from sub-images: (i) suggested method-1, a standard ML-based method, and (ii) suggested method-2, an ensemble method based on ResNet-50. The rim-one database of the medical image ana-lysis group (MIAG) is used for proposed method- 1 . To test the robustness, they employ three more databases: MIAG rim-one r3, Drishti-GS, and the original data-base. To create a huge database, all databases, inclu-ding rim-one r1, r2, r3, Kristi-GS, and original, are integrated into proposed method-2. At full size, Method-1 produced the greatest results with one order 2D-FBSE-EWT. For databases $\mathrm{r} 1, \mathrm{r} 2$, and $\mathrm{r} 12$, the best accuracy is 98.21 percent using RF, 90 percent using SVM, and 95.51 percent using RF classifier in method 1. Approach 2 uses one order 2D-FBSE-EWT method-based subimages at full frequency fusion ensemble's scale to achieve improved results, with accuracy, sen-sitivity, specificity, and Area Under Curve of ROC of 91.1 percent, 94.3 percent, 83.3 percent, and 0.96 per-cent, respectively.

\section{Strabismus}

Strabismus A good number of researchers have been studied and conducted for the automatic detection of Strabismus. The (Zolkifli et al., 2021) system is conducted into 4 stages which are image acquisition, preprocessing, locating the glint on the irises and distance, and finally the classification for the strab-ismus types. To develop their algorithm, they used MATLAB (R2018b) image processing toolkit. For the CAVE, all the images are classified into normal indi-viduals. Image 37 is the only hypertropia type found in the eye disease dataset while the other images are classified in esotropia types. In (Lu et al., 2019) a deep neural network was utilized to analyze 5685 photos containing strabismus. For training and testing, 3409 and 2276 photos are used. There are 701 strabismus photos and 2708 normal images in the training dataset. The test dataset contains 470 strabismus photos and 1806 normal ones. They proposed a new method that is made up of two stages- (i) Eye segmentation is perfor-med using R-FCN. (ii) To categorize the segmented eye areas as Strabismus or normal, a CNN is used. Result of first experiment: $1^{\text {st }}$ CNN Network - Sensitivity$0.9330 \%$, Specificity- $0.9617 \%$, Accuracy- $0.9389 \%$, AUC- $0.9865 \% .2^{\text {nd }} C N N$ Network - Sensitivity-0.95

UniversePG I www.universepg.com
$24 \%$, Specificity-0.9648\%, Accuracy-0.9512\%, AUC$0.9876 \%$. In (Zolkifli et al., 2021), The method used here - 1. Image Acquisition, 2. pre-processing, 3. Feature extraction that includes (i) Sobel Edge Dete-ction (ii) Hough Transform. Using the Cave dataset, they achieved Avg Mean square error $=0.0003 \%$, Avg Peak signal to noise ratio $=84.3540 \%$. Using the Eye disease dataset, they achieved Avg Mean square error= $0.0012 \%$, Avg Peak signal to noise ratio $=76.3595 \%$. Using the Siblings DB dataset Avg Mean square error $=0.0004 \%$, Avg Peak signal to noise ratio $=82$. 4973\%. The method was broken down into six parts (Simoes et al., 2019) including picture dataset acquisition, limb and eye localization, sclera segmentation and reconstruction, corners of the eyes, and classification in normal and strabismic patients. This approach is used to analyze a private strabismus dataset collected in a Sao Luis, Brazil, ophthalmology office. To develop their method, they used 225 images of 45 patients.YOLOv3 was used to locate the regions of the eyes and limbs, and data augmentation was employed to enlarge the training set in this stage. After this training set grew to 1280 images. They used U-net to perform scale segmentation. UBIRIS.v2 and SSRBC 2017 were the datasets utilized to train for the sclera segmentation stage. Hirschberg tests were employed in the five gaze positions DEXTRO, INFRA, LEVO, PP, and SUPRA to detect strabismus. The approach of PP and SUPRA placements produced the best results in identifying strabismic patients. The PP position had a sensitivity of $95.8 \%$, a specificity of $100 \%$, and a precision of $96.6 \% .93 \%$ of the youngsters $(125 / 133)$ had at least one successful app measurement, according to (Cheng et al., 2021). Six people were identified as having strabismus, including four exotropia $(10 \triangle$, $10 \triangle, 14 \triangle$, and $18 \triangle$ ), one continuous esotropia (25 $\triangle$ ), and one accommodating esotropia $14 \triangle$ ). Based on the ROC curve, the appropriate threshold for the application to detect strabismus is 3.0, with the highest $83.0 \%$ sensitivity, $100 \%$ specificity, and $100 \%$ accuracy. One child with accommodative exotropia would have been missed by the app if this criterion had been used,three cases of intermittent exotropia would have been missed if traditional screening had been used. A total number of 38 patients with strabismus were included in the research (Yeh et al., 2021). The APCT and the VR-based system's angle of ocular deviation had a good outstanding association (ICC $=0.897$ (range: 
0.810-0.945)). The $95 \%$ confidence intervals were 11.32 PD. In the subgroup analysis, a significant difference between esotropia and exotropia was

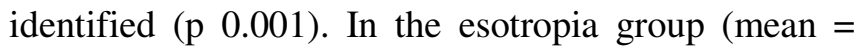
4.65 PD), the amount of ocular deviation measured by the VR-based system was more than that measured by the APCT, but in the exotropia group (mean $=3.01$
PD), the amount of ocular deviation indicated by the VR-based system was lower. The ICC was 0.962 (range: $0.902-0.986$ ) in the esotropia group and 0.862 (range: $0.651-0.950$ ) in the exotropia group. The 95 percent limits of agreement in the esotropia and exotropia groups were 6.62 PD and 11.25 PD each. The Table shows the result of DR, GL, and Strabismus -

Table 5: DR, GL and Strabismus results.

\begin{tabular}{|c|c|c|c|c|c|}
\hline $\begin{array}{c}\text { Eye } \\
\text { Disease }\end{array}$ & $\begin{array}{l}\text { Architecture / } \\
\text { Classifier }\end{array}$ & Layers & Model & Ref. & Results \\
\hline \multirow[t]{24}{*}{ DR } & o_OSolution & & $\mathrm{CNN}$ & (Gondal et al., 2017) & $\begin{array}{c}\text { Sensitivity }=93: 6 \%, \text { Specificity }=97: 6 \%, \\
\text { Area Under Curve }=95: 4 \%\end{array}$ \\
\hline & o_OSolution & & $\mathrm{CNN}$ & (Quellec et al., 2017) & Area Under Curve $=95: 4 \%$ \\
\hline & ImageNet & & $\mathrm{CNN}$ & (Roy et al., 2017) & Kappa Score $=86 \%$ \\
\hline & U-Net & & $\mathrm{CNN}$ & (Li et al., 2017) & Area Under Curve $=96 \%$ \\
\hline & OxfordNet & & $\mathrm{CNN}$ & (Grinsven et al., 2016) & $\begin{array}{c}\text { Sensitivity }=91: 90 \%, \text { Specificity }=91: 40 \%, \\
\text { Area Under Curve }=97: 2 \%\end{array}$ \\
\hline & Inception-V4 & & $\mathrm{CNN}$ & (Sayres et al., 2019) & Accuracy $=88: 4 \%$ \\
\hline & $\begin{array}{l}\text { AlexNet, GoogLe } \\
\text { Net, VGGNets }\end{array}$ & & $\mathrm{CNN}$ & (Li et al., 2017) & $\begin{array}{c}\text { Sensitivity }=86: 03 \%, \text { Specificity }=97: 11 \% \\
\text { Area Under Curve }=98: 34 \%, \text { Accuracy }= \\
92: 01 \%\end{array}$ \\
\hline & Inception-V3 & & $\mathrm{CNN}$ & (Umapathy et al., 2019,) & Accuracy $=88: 8 \%$ \\
\hline & ResNet50 & & $\mathrm{CNN}$ & (Li et al., 2019) & Area Under Curve $=92: 6 \%$, Accuracy $=96: 3 \%$ \\
\hline & AlexNet & & $\mathrm{CNN}$ & (Harangi et al., 2019,) & Accuracy $=90: 07 \%$ \\
\hline & Softmax & 8 & $\mathrm{CNN}$ & (Hemanth et al., 2020) & $\begin{array}{c}\text { Sensitivity }=94 \%, \text { Specificity }=98 \%, \text { Prec } \\
=94 \%, \text { FSc }=94 \%, \text { GMean }=95 \%, \\
\text { Accuracy }=97 \%\end{array}$ \\
\hline & Softmax & 29 & $\mathrm{CNN}$ & (Doshi et al., 2016) & Kappa Score $=39: 96 \%$ \\
\hline & Decision Trees & 6 & $\mathrm{CNN}$ & (Gargeya et al., 2017) & $\begin{array}{c}\text { Sensitivity }=93 \%, \text { Specificity }=87 \%, \text { Area } \\
\text { Under Curve }=94 \%\end{array}$ \\
\hline & Softmax & 28 & $\mathrm{CNN}$ & (Gargeya et al., 2017) & $\begin{array}{c}\text { Kappa Score }=75: 4 \%, \text { Prec }=88: 20 \%, \\
\text { Sensitivity }=95 \%, \text { Accuracy }=85 \%\end{array}$ \\
\hline & Softmax & 17 & $\mathrm{CNN}$ & (Jiang et al., 2017) & Accuracy $=75: 70 \%$ \\
\hline & Softmax & 13 & $\mathrm{CNN}$ & (Hajabdollahi et al., 2019) & Sensitivity $=95 \%$, Specificity $=30 \%$ \\
\hline & Softmax & 16 & $\mathrm{CNN}$ & (Bir et al., 2020) & Accuracy $=94: 5 \%$ \\
\hline & Softmax & 10 & $\mathrm{CNN}$ & (Yang et al., 2017) & $\begin{array}{c}\text { Sensitivity }=95: 90 \%, \text { Specificity }=89: 90 \% \\
\text { Area Under Curve }=96: 87 \%\end{array}$ \\
\hline & Softmax & 16 & $\mathrm{CNN}$ & (Jain et al., 2018) & $\begin{array}{c}\text { Sensitivity }=88: 85 \%, \text { Specificity }=96 \%, \\
\text { Accuracy }=91: 92 \%\end{array}$ \\
\hline & Softmax & 17 & $\mathrm{CNN}$ & (de Almeda et al., 2012) & Sensitivity $=91: 1 \%$, Specificity $=90: 8 \%$ \\
\hline & Softmax & 16 & $\mathrm{CNN}$ & (de La Torre et al., 2020) & Area Under Curve $=96: 1 \%$ \\
\hline & Softmax & 3 & $\mathrm{CNN}$ & (Abbas et al., 2017) & $\begin{array}{c}\text { Sensitivity }=92.18 \%, \text { Specificity }=94.50 \%, \\
\text { Area Under Curve }=92.4 \%\end{array}$ \\
\hline & $\mathrm{RF}$ & 10 & $\mathrm{CNN}$ & (Orlando et al., 2018) & $\begin{array}{c}\text { Sensitivity }=97.21 \%, \text { Area Under Curve }= \\
93.47 \%\end{array}$ \\
\hline & SVM & 3 & $\mathrm{DBN}$ & (Arunkumar et al., 2017) & $\begin{array}{c}\text { Sensitivity }=79.32 \%, \text { Specificity }=97.89 \%, \\
\text { Accuracy }=96.73 \%\end{array}$ \\
\hline \multirow[t]{2}{*}{ GL } & ResNet & & $\mathrm{CNN}$ & (Asaoka et al., 2019) & Area Under Curve $=99.7 \%$ \\
\hline & VGG-19 & & $\mathrm{CNN}$ & (An et al., 2019) & Area Under Curve $=96: 3 \%$ \\
\hline
\end{tabular}




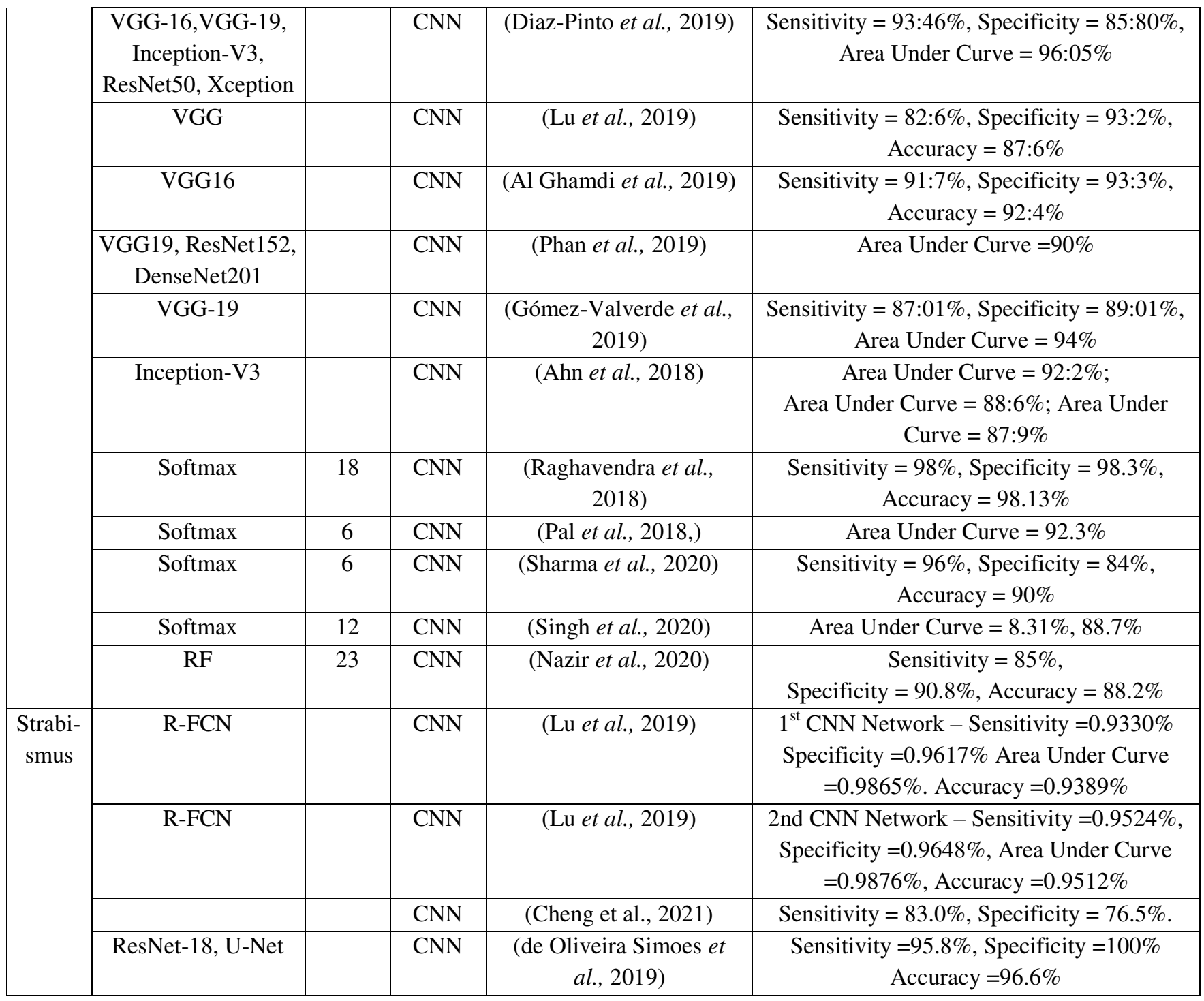

Another Table is given below that provides us information on which articles have used which type of results -

Table 6: Result types used in selected articles.

\begin{tabular}{|c|c|c|c|c|c|c|c|c|c|c|}
\hline References & Babak & PPV & Prev & FSc & $\begin{array}{l}\text { Kappa } \\
\text { Score }\end{array}$ & Specificity & Sensitivity & $\begin{array}{c}\text { Area } \\
\text { Under Curve }\end{array}$ & Accuracy & GMean \\
\hline $\begin{array}{l}\text { (Gondal } \text { et al., 2017), } \\
\text { (Van Grinsven } \text { et al., } \\
\text { 2016; Gargeya, } \text { et al., } \\
\text { 2017; Yang } \text { et al., } \\
\text { 2017; Abbas } \text { et al., } \\
\text { 2017; Diaz-Pinto } \text { et al., } \\
\text { 2019; Gómez- } \\
\text { Valverde } \text { et al., 2019) }\end{array}$ & $x$ & $x$ & $x$ & $x$ & $x$ & $\checkmark$ & $\checkmark$ & $\checkmark$ & $x$ & $x$ \\
\hline $\begin{array}{c}\text { (Jain } \text { et al., 2018, } \\
\text { Arunkumar } \text { et al., } \\
\text { 2017; Lu } \text { et al., 2019; } \\
\text { Al Ghamdi } \text { et al., } \\
\text { 2019; Raghavendra et } \\
\text { al., 2018; Sharma et }\end{array}$ & $x$ & $x$ & $x$ & $x$ & $x$ & $\checkmark$ & $\checkmark$ & $x$ & $\checkmark$ & $x$ \\
\hline
\end{tabular}




\begin{tabular}{|c|c|c|c|c|c|c|c|c|c|c|}
\hline \begin{tabular}{|c|} 
al., 2020; Nazir et al., \\
2020; de Oliveira \\
Simoes et al., 2019)
\end{tabular} & & & & & & & & & & \\
\hline $\begin{array}{c}\text { (Quellec } \text { et al., 2017; } \\
\text { Li } \text { et al., 2017; La } \\
\text { Torre } \text { et al., 2020; } \\
\text { Asaoka } \text { et al., 2019; } \\
\text { An } \text { et al., 2019; Phan } \\
\text { et al., 2019; Ahn } \text { et al., } \\
\text { 2018; Pal } \text { et al., 2018; } \\
\text { Singh } \text { et al., 2020) }\end{array}$ & $x$ & $x$ & $x$ & $x$ & $x$ & $x$ & $x$ & $\checkmark$ & $x$ & $x$ \\
\hline $\begin{array}{l}\text { (Sayres } \text { et al., 2019; } \\
\text { Umapathy } \text { et al., 2019; } \\
\text { Harangi } \text { et al., 2019; } \\
\text { Jiang } \text { et al., 2017; Bir } \\
\quad \text { et al., 2020) }\end{array}$ & $x$ & $x$ & $x$ & $x$ & $x$ & $x$ & $x$ & $x$ & $\checkmark$ & $x$ \\
\hline $\begin{array}{l}\text { (Roy et al., 2017; } \\
\text { Doshi et al., 2016) }\end{array}$ & $x$ & $x$ & $x$ & $x$ & $\checkmark$ & $x$ & $x$ & $x$ & $x$ & $x$ \\
\hline (Li et al., 2017) & $x$ & $x$ & $x$ & $x$ & $x$ & $\checkmark$ & $\checkmark$ & $\checkmark$ & $\checkmark$ & $x$ \\
\hline (Li et al., 2019) & $x$ & $x$ & $x$ & $x$ & $x$ & $x$ & $x$ & $\checkmark$ & $\checkmark$ & $x$ \\
\hline (Hemanth et al., 2020) & $x$ & $x$ & $\checkmark$ & $\checkmark$ & $x$ & $\checkmark$ & $\checkmark$ & $x$ & $\checkmark$ & $\checkmark$ \\
\hline (Gargeya et al., 2017) & $x$ & $x$ & $\checkmark$ & $\sqrt{ }$ & $x$ & $x$ & $\checkmark$ & $x$ & $\checkmark$ & $x$ \\
\hline $\begin{array}{c}\text { (Hajabdollahi } \text { et al., } \\
\text { 2019); (de Almeida } \text { et } \\
\text { al., 2012). }\end{array}$ & $x$ & $x$ & $x$ & $x$ & $x$ & $\checkmark$ & $\checkmark$ & $x$ & $x$ & $x$ \\
\hline (Orlando et al., 2018) & $x$ & $x$ & $x$ & $x$ & $x$ & $x$ & $\checkmark$ & $\checkmark$ & $x$ & $x$ \\
\hline (Lu et al., 2019) & $x$ & $x$ & $x$ & $x$ & $x$ & $\checkmark$ & $\checkmark$ & $\checkmark$ & $\checkmark$ & $x$ \\
\hline
\end{tabular}

\section{Selected Articles Models Strength and Weakness Table}

The Table shows us the strength, weaknesses, accuracy of top-1 and top-5, parameters, and the depth of selected articles models.

Table 7: The Table shows us the strength, weakness.

\begin{tabular}{|c|c|c|c|c|c|c|}
\hline Models & $\begin{array}{c}\text { Accuracy of } \\
\text { Top-1 }\end{array}$ & $\begin{array}{l}\text { Accuracy } \\
\text { of Top-5 }\end{array}$ & Parameters & Depth & Strength & Weakness \\
\hline ResNet50 & 0.769 & 0.921 & $\mid 25,636,712$ & - & $\begin{array}{l}\text { Itreduces the vanishing-gradient } \\
\text { problem, the total number of } \\
\text { parameters, Strengthens feature } \\
\text { propagation, encourages feature } \\
\text { reuse. }\end{array}$ & $\begin{array}{l}\text { One major weakness } \\
\text { seems to be that the dee- } \\
\text { per network takes weeks } \\
\text { of training before it can } \\
\text { be used in real-world } \\
\text { scenarios. }\end{array}$ \\
\hline ResNet152 & 0.766 & 0.931 & $60,419,944$ & - & $\begin{array}{c}\text { A huge number of networks can be } \\
\text { trained easily without increasing the } \\
\text { training error percentage. }\end{array}$ & Not defined yet. \\
\hline VGG16 & 0.713 & 0.901 & $138,357,544$ & 23 & $\begin{array}{l}\text { It's a great building block for learning } \\
\text { purposes and easy to implement. }\end{array}$ & It's very slow to train. \\
\hline VGG19 & 0.713 & 0.900 & $143,667,240$ & 26 & $\begin{array}{l}\text { It's better performance than the } \\
\text { VGG16 model. }\end{array}$ & It takes more memory. \\
\hline AlexNet & 0.6330 & 0.8460 & 62378344 & 8 & $\begin{array}{c}\text { AlexNet allows multi GPU training } \\
\text { so bigger models can be trained here } \\
\text { easily and it also helps to reduce }\end{array}$ & $\begin{array}{l}\text { The model is not very } \\
\text { deep and It doesn't do a } \\
\text { good job with color }\end{array}$ \\
\hline
\end{tabular}




\begin{tabular}{|c|c|c|c|c|c|c|}
\hline & & & & & training time. & photos. \\
\hline GoogleNet & 0.7480 & 0.922 & 23000000 & 22 & $\begin{array}{c}\text { It trains faster than VGG models and } \\
\text { takes less memory space. }\end{array}$ & Not defined yet. \\
\hline $\begin{array}{c}\text { DenseNet20 } \\
1\end{array}$ & 0.773 & 0.936 & $20,242,984$ & 201 & $\begin{array}{c}\text { Itreduces the parameters, vanishes } \\
\text { gradient problems, etc. }\end{array}$ & Not defined yet. \\
\hline Inception v3 & 0.779 & 0.937 & $23,851,784$ & 48 & $\begin{array}{c}\text { Compared to its contemporaries In- } \\
\text { ception v3 can achieve the lowest } \\
\text { error rates. }\end{array}$ & $\begin{array}{c}\text { The architecture is simplified using } \\
\text { more inception modules than } \\
\text { inception v3. }\end{array}$ \\
\hline Inception v4 & 0.80 & 0.95 & $43,00,0000$ & 22 & & - \\
\hline
\end{tabular}

\section{Researh GAP}

We have studied more than 70 articles here. There are various study gaps that academics have neglected to fill in prior DED studies. They need to increase the effectiveness of different eye diseases detection. We addressed some of the issues that are given here:

Thriving Stronger DL models in medical imaging, DL has a very good contribution and disease diagnosis. However, it is tough to create more effective deep neural networks. A key solution is that the computational power can be increased by increasing the network capacity but there exists a chance of over-fitting. Creating an object-based model is another solution. Training on Minimum Data for learning, the DL software was employed by a very good amount of retinal images. When the dataset is few the DL doesn't provide the expected result with good accuracy. For that, there are available 2 solutions. The first is to make use of the length of enhancement methods where shifting, cropping, color building, and rotation are included. Another is to retrieve training data by employing feeble learning algorithms. Corresponding DL architecture for Medical Imaging Most of the DL, there are used different TL frameworks like AlexNet, GoogleNet, ResNet, VGGNet, etc. Generally, TL frameworks are created for the objects like flowers, animals, and so much more. So these architectures are not suitable enough for medical pictures. A new TL can be created that specializes in learning relevant medical images. Integrating TL and Cloud Computing Hereafter, to detect Eye diseases from the images of the retinal fundusthe neuralnetworks and cloud computing may be associated. For example, people from different communities could use their mobile phone cameras to capture the eye images individually. Then these images could be transmitted to the cloud comp-uting system where the eye diseases detection system is created. UniversePG I www.universepg.com
Finally, the system will identify the eye diseases and show the result to the patient.

\section{CONCLUSION:}

The survey paper provides an extensive overview of different eye diseases detection techniques which are Strabismus, DR, and GL. To acquire this goal, we conducted an appropriate comprehensive review of different publications. After selecting the final relevant publications, the study has been analyzed from the view of (i) Dataset, (ii) Image processing techniques, and (iii) method employed for classification. We categorized the survey into three eye diseases parts which are Strabismus, DR, and GL. The survey includes different articles where TL, DL, and ML approaches are adopted. We also find out some limitations from different articles here. At first, we shrink down the review which was conducted from January 2016 to June 2021. Then based on DL approaches, because of their state of art performance we limited the review. Finally, we concentrated on different keyword colle-ctions which helped us to provide a veil of eye diseases area. In the future, we hope that our research will be expanded more based on recent publications.

\section{ACKNOWLEDGEMENT:}

First and foremost, I acknowledge Allah's grace because it would not have been possible without it. In addition, I would like to express my gratitude to the coauthors and respected professors of the Bangladesh University of Business and Technology (BUBT) Department of Computer Science and Engineering for supervising me and giving us the necessary assistance to complete the research.

\section{CONFLICTS OF INTEREST:}

There are no conflicts of interest to be disclosed by any of the authors. 


\section{REFERENCES:}

1) Abbas, Q., Fondon, I., Jiménez, (2017). Automatic recognition of severity level for diagnosis of diabetic retinopathy using deep visual features. Medical \& biological engineeering \& computing, 55(11), 1959-1974.

https://link.springer.com/article/10.1007/s11517-

$\underline{017-1638-6}$

2) Ahn, J. M., Kim, S., Ahn, K. S., (2018). A deep learning model for the detection of both advanced and early glaucoma using fundus photography. PloS one, 13(11), e0207982. https://doi.org/10.1371/journal.pone.0211579

3) Alghamdi, M., \& Abdel-Mottaleb, M. (2021). A Comparative Study of Deep Learning Models for Diagnosing Glaucoma From Fundus Images. IEEE Access, 9, 23894-23906. https://doi.org/10.1109/ACCESS.2021.3056641

4) Al Ghamdi, M., Li, M., \& Abou Shousha, M. (2019). Semi-supervised transfer learning for convolutional neural networks for glaucoma detection. In ICASSP 2019-2019 IEEE International Conference on Aco-ustics, Speech and Signal Processing (pp. 3812-3816). IEEE. https://doi.org/10.1109/ICASSP.2019.8682915

5) An, G., Omodaka, K., Hashimoto, K., Tsuda, S., (2019). Glaucoma diagnosis with machine learning based on optical coherence tomography and color fundus images. $J$. of healthcare engineering, 2019. https://doi.org/10.1155/2019/4061313

6) Arunkumar, R., \& Karthigaikumar, P. (2017). Multi-retinal disease classification by reduced deep learning features. Neural Computing and Applications, 28(2), 329-334.

7) Asaoka, R., Tanito, M., Shibata, N., (2019). Validation of a deep learning model to screen for glaucoma using images from different fundus cameras and data augmentation. Ophthalmology Glaucoma, 2(4), 224-231.

https://doi.org/10.1016/j.ogla.2019.03.008

8) Azam MS, Rahman A, Iqbal SMHS, and Ahmed MT. (2020). Prediction of liver diseases by using few machine learning based approaches, Aust. J. Eng. Innov. Technol., 2(5), 85-90. https://doi.org/10.34104/ajeit.020.085090

9) Bahrami, M., \& Sajedi, H. (2018). Prediction of diabetic retinopathy based on a committee of random forests. International Journal of Intelligent Machines and Robotics, 1(2), 133-139.

10) Bhaskaranand, M., Ramachandra, C., Bhat, S., (2019). The value of automated diabetic retinopathy screening with the EyeArt system: a study of more than 100,000 consecutive encounters from people with diabetes. Diabetes technology \& therapeutics, 21(11), 635-643.

https://doi.org/10.1089/dia.2019.0164

11) Bir, P., \& Balas, V. E. (2020). A Review on Medical Image Analysis with Convolutional Neural Networks. In 2020 IEEE International Conference on Computing, Power and Communication Technologies (pp. 870-876). IEEE. https://doi.org/10.1109/GUCON48875.2020.9231203

12) Chaudhary, P. K., \& Pachori, R. B. (2021). Automatic diagnosis of glaucoma using two-dimensional Fourier-Bessel series expansion based empirical wavelet transform. Biomedical Signal Processing and Control, 64, 102237. https://doi.org/10.1016/j.bspc.2020.102237

13) Cheng, W., Lynn, M. H., Pundlik, S., (2021). A smartphone ocular alignment measurement app in school screening for strabismus. BMC ophthalmology, 21(1), 1-10.

14) Decencière, E., Zhang, X., Lay, B., (2014). Feedback on a publicly distributed image database: the Messidor database. Image Analysis \& Stereology, 33(3), 231-234. https://www.ias-iss.org/ojs/IAS/article/view/1155

15) de Almeida, J. D. S., Silva, A. C., de Paiva, A. C., (2012). Computational methodology for automatic detection of strabismus in digital images through Hirschberg test. Computers in biology and medicine, 42(1), 135-146. https://doi.org/10.1016/j.compbiomed.2011.11.001

16) de Figueiredo, L. A., Dias, J. V. P., Polati, M., (2021). Strabismus and Artificial Intelligence App: Optimizing Diagnostic and Accuracy. Translational Vision Science \& Technol., 10(7), 2222. https://doi.org/10.1167/tvst.10.7.22

17) de La Torre, J., Valls, A., \& Puig, D. (2020). A deep learning interpretable classifier for diabetic retinopathy disease grading. Neurocom., 396, 465476. https://doi.org/10.1016/j.neucom.2018.07.102

18) de Oliveira Simoes, T., Souza, J. C., de Almeida, (2019). Automatic Ocular Alignment Evaluation 
for Strabismus Detection Using U-NET and Res Net Networks. In $20198^{\text {th }}$ Brazilian Con-ference on Intelligent Systems (pp. 239-244). IEEE. https://doi.org/10.1109/BRACIS.2019.00050

19) Diaz-Pinto, A., Morales, S., Naranjo, V., (2019). CNNs for automatic glaucoma assessment using fundus images: an extensive validation. Biomedical engineering online, 18(1), 1-19.

20) Doshi, D., Shenoy, A., \& Gharpure, P. (2016). Diabetic retinopathy detection using deep neural networks. In 2016 International Conference on Computing, Analytics and Security Trends (p. 261-266). IEEE.

https://doi.org/10.1109/CAST.2016.7914977

21) Gargeya, R., \& Leng, T. (2017). Automated identification of diabetic retinopathy using deep learning. Ophthalmology, 124(7), 962-969. https://doi.org/10.1016/j.ophtha.2017.02.008

22) Gómez-Valverde, J. J., Antón, A., Fatti, G., (2019). Automatic glaucoma classification using color fundus images based on convolutional neural networks and transfer learning. Biomedical optics express, 10(2), 892-913.

23) Gondal, W. M., Köhler, J. M., Grzeszick, R., (2017). Weakly-supervised localization of diabetic retinopathy lesions in retinal fundus images. In 2017 IEEE international conference on image processing (ICIP) (pp. 2069-2073). IEEE. https://doi.org/10.1109/ICIP.2017.8296646.

24) Gulshan, V., Peng, L., Stumpe, M. (2016). Development and validation of a deep learning algorithm for detection of diabetic retinopathy in retinal fundus photographs. Jama, 316(22), 24022410. https://doi.org/10.1001/jama.2016.17216.

25) Gupta, S., \& Gagneja, A. (2014). Proposed iris recognition algorithm through image acquisition technique. International J. of Advanced Research in Computer Science and Software Engineering, 4(2), 269-270.

26) Hajabdollahi, M., Esfandiarpoor, R., Najarian, K., (2019). Hierarchical pruning for simp-lification of convolutional neural networks in diabetic retinopathy classification. In $201941^{s t}$ Annual International Conference of the IEEE Engineering in Medicine and Biology Society (EMBC) (pp. 970-973). IEEE. https://doi.org/10.1109/EMBC.2019.8857769
27) Harangi, B., Toth, J., Baran, A., \& Hajdu, A. (2019). Automatic screening of fundus images using a combination of convolutional neural network and handcrafted features. In $201941^{s t}$ Annual International Conference of the IEEE Engineering in Medicine and Biology Society (EMBC) (pp. 2699-2702). IEEE. https://doi.org/10.1109/EMBC.2019.8857073

28) Hemanth, D. J., Deperlioglu, O., \& Kose, U. (2020). An enhanced diabetic retinopathy detection and classification approach using deep convolutional neural network. Neural Computing and Applications, 32(3), 707-721.

29) Jain, L., Murthy, H. S., Patel, C., \& Bansal, D. (2018). Retinal eye disease detection using deep learning. In $201814^{\text {th }}$ International Conference on Information Processing (p1-6). IEEE. https://doi.org/10.1109/ICINPRO43533.2018.9096 838

30) Jiang, Y., Wu, H., \& Dong, J. (2017). Automatic screening of diabetic retinopathy images with convolution neural network based on caffe framework. In Proceedings of the $1^{\text {st }}$ Intern. Conf. on Medical and Health Informatics 2017 (pp. 9094). https://doi.org/10.1145/3107514.3107523

31) Khaleduzzaman K, Mahmud $\mathrm{MH}$, and Podder PK. (2021). Detection and implementation of blood group and $\mathrm{Hb}$ level by image processing techniques. Aust. J. Eng. Innov. Technol., 3(5), 73-81. https://doi.org/10.34104/ajeit.021.073081

32) Kumar, S., Adarsh, A., Kumar, B., \& Singh, A. K. (2020). An automated early diabetic retinopathy detection through improved blood vessel and optic disc segmentation. Optics \& Laser Technology, 121, 105815. https://doi.org/10.1016/j.optlastec.2019.105815

33) Li, G., Zheng, S., \& Li, X. (2017). Exudate detection in fundus images via convolutional neural network. In International Forum on Digital TV and Wireless Multimedia Communications (pp. 193-202). Springer, Singapore. https://link.springer.com/chapter/10.1007/978-981$\underline{10-8108-8 \quad 18}$

34) Li, X., Liu, W., \& Wang, T. (2017). Convolutional neural networks based transfer learning for diabetic retinopathy fundus image classification. In $201710^{\text {th }}$ international congress on 
image and signal processing, biomedical engineeering and informatics (pp. 1-11). IEEE. https://doi.org/10.1109/CISP-BMEI.2017.8301998

35) Li, X., Hu, X., Yu, L., Zhu, L., (2019). CANet: cross-disease attention network for joint diabetic retinopathy and diabetic macular edema grading. IEEE transact. on medical imaging, 39(5), 14831493. https://doi.org/10.1109/TMI.2019.2951844

36) Lu, J., Feng, J., Fan, Z., Huang, L., (2019). Automated strabismus detection based on deep neural networks for telemedicine application. Knowledge-based systems. 13.

37) Nazir, T., Irtaza, A., Javed, A., (2020). Retinal image analysis for diabetes-based eye disease detection using deep learning. Appl. Sci., 10(18), 6185. https://doi.org/10.3390/app10186185

38) Orlando, J. I., Prokofyeva, E., Del Fresno, M., (2018). An ensemble deep learning based approach for red lesion detection in fundus images. Computer methods and programs in biomedicine, 153, 115-127. https://doi.org/10.1016/j.cmpb.2017.10.017

39) Pal, A., Moorthy, M. R., \& Shahina, A. (2018). G-eyenet: A convolutional autoencoding classifier framework for the detection of glaucoma from retinal fundus images. In 2018 25th IEEE international conference on image processing (ICIP) (pp. 2775-2779). IEEE. https://doi.org/10.1109/ICIP.2018.8451029

40) Patil, N., Patil, P. N., \& Rao, P. V. (2021). Convolution neural network and deep-belief network (DBN) based automatic detection and diagnosis of Glaucoma. Multimedia Tools and Applications, 80(19), 29481-29495. https://link.springer.com/article/10.1007/s11042-0 21-11087-5

41) Phan, S., Satoh, S. I., Yoda, Y., \& Oshika, T. (2019). Evaluation of deep convolutional neural networks for glaucoma detection. Japanese j. of ophthalmology, 63(3), 276-283.

https://link.springer.com/article/10.1007/s10384-0 19-00659-6

42) Quellec, G., Charrière, K., Boudi, Y., (2017). Deep image mining for diabetic retinopathy screening. Medical image analysis, 39, 178-193. https://doi.org/10.1016/j.media.2017.04.012.
43) Raghavendra, U., Fujita, H., Bhandary, S. V., (2018). Deep convolution neural network for accurate diagnosis of glaucoma using digital fundus images. Information Sciences, 441, 41-49. https://doi.org/10.1016/j.ins.2018.01.051

44) Ramasamy, L. K., Kadry, S., \& Damaševičius, R. (2021). Detection of diabetic retinopathy using a fusion of textural and ridgelet features of retinal images and sequential minimal optimazation classifier. PeerJ computer science, 7.

45) Roy, P., Cao, K., Sedai, S., (2017). A novel hybrid approach for severity assessment of diabetic retinopathy in colour fundus images. In 2017 IEEE $14^{\text {th }}$ International Symposium on Biomedical Imaging (pp. 1078-1082). IEEE. https://doi.org/10.1109/ISBI.2017.7950703.

46) Sahlsten, J., Jaskari, J., Kivinen, J., (2019). Deep learning fundus image analysis for diabetic retinopathy and macular edema grading. Scientific reports, 9(1), 1-11.

https://www.nature.com/articles/s41598-019-4718 $\underline{1-\mathrm{w}}$

47) Saranya, P., \& Prabakaran, S. (2020). Automatic detection of non-proliferative diabetic retinopathy in retinal fundus images using con-volution neural network. Journal of Ambient Intelligence and Humanized Computing, 1-10. https://link.springer.com/article/10.1007/s12652$\underline{020-02518-6}$

48) Sayres, R., Taly, A., Blumer, K., (2019). Using a deep learning algorithm and integrated gradients explanation to assist grading for diabetic retinopathy. Ophthalmology, 126(4), 552-564. https://doi.org/10.1016/j.ophtha.2018.11.016

49) Sharma, A., Agrawal, M., Roy, S. D., \& Gupta, V. (2020). Automatic glaucoma diagnosis in digital fundus images using deep CNNs. In $A d$ vances in Computational Intelligence Techniques (pp. 37-52). Springer.

https://doi.org/10.1109/ISPCC48220.2019.8988512

50) Simon, S. (2019). Retinal Image Enhancement and Eye Disease Identification. In proceedings of the International Conference on Systems, Energy \& Environment (ICSEE). https://papers.ssrn.com/sol3/Papers.cfm?abstract_i $\underline{\mathrm{d}=3445915}$ 
51) Singh, L. K., \& Garg, H. (2020). Automated glaucoma type identification using machine learning or deep learning techniques. In Advancement of Machine Intelligence in Interactive Medical Image Analysis (pp. 241-263). Springer. https://link.springer.com/chapter/10.1007/978-98115-1100-4_12

52) Sisodia, D. S., Nair, S., \& Khobragade, P. (2017). Diabetic retinal fundus images: Preprocessing and feature extraction for early detection of diabetic retinopathy. Biomedical and Pharmacology Journal, 10(2), 615-626.

https://dx.doi.org/10.13005/bpj/1148

53) Tufail, A., Rudisill, C., Egan, C., Kapetanakis, V. V., (2017). Automated diabetic retinopathy image assessment software: diagnostic accuracy and cost-effectiveness compared with human graders. Ophthalmology, 124(3), 343-351.

https://doi.org/10.1016/j.ophtha.2016.11.014

54) Umapathy, A., Sreenivasan, A., Nairy, D. S., (2019). Image Processing, Textural Feature Extraction and Transfer Learning based detection of Diabetic Retinopathy. In Proceedings of the $20199^{\text {th }}$ International Conference on Bioscience, Biochemistry and Bioinform. (pp. 17-21). https://doi.org/10.1109/ACCESS.2020.3015258

55) Umesh, L., Mrunalini, M., \& Shinde, S. (2016). Review of image processing and machine learning techniques for eye disease detection and classification. International Research Journal of Engineering and Technology, 3(3), 547-551.

56) Van Grinsven, M. J., van Ginneken, B., Hoyng, (2016). Fast convolutional neural network training using selective data sampling: Application to hemorrhage detection in color fundus images. IEEE transact. on med. imag., 35(5), 1273-1284. https://dx.doi.org/10.1109/TMI.2016.2526689
57) Yang, Y., Li, T., \& Zhang, W. (2017). Lesion detection and grading of diabetic retinopathy via two-stages deep convolutional neural networks. In International Conference on Medical Image Computing and Computer-Assisted Intervention (pp. 533-540). Springer, Cham. https://link.springer.com/chapter/10.1007/978-3-3 19-66179-7 61

58) Yeh, P. H., Liu, C. H., Sun, M. H.,. (2021). To measure the amount of ocular deviation in strabismus patients with an eye-tracking virtual reality headset. BMC ophthalmology, 21(1), 1-8. https://bmcophthalmol.biomedcentral.com/articles/ 10.1186/s12886-021-02016-Z

59) Zago, G. T., Andreão, R. V., Dorizzi, B., (2020). Diabetic retinopathy detection using red lesion localization and convolutional neural networks. Com. in biology and medicine, 116, 103537. https://doi.org/10.1016/j.compbiomed.2019.103537

60) Zhang, W., Zhong, J., Yang, S., Gao, Z., Hu, J., (2019). Automated identification and grading system of diabetic retinopathy using deep neural networks. Knowledge-Based Systems, 175, 1225. https://doi.org/10.1016/j.knosys.2019.03.016

61) Zolkifli, N. S., Nazari, A., Akir, R. M., \& Vajravelu, A. (2021). Range Detection of Strabismus based on the Distance and Coordinates of the Iris. International $J$. of Advanced Computer Systems and Software Engineering, 2(1), 23-29.

62) Zolkifli, N. S., \& Nazari, A. (2020). Tracing of Strabismus Detection Using Hough Transform. In 2020 IEEE Student Conference on Research and Development (pp. 313-318). IEEE. https://doi.org/10.1109/SCOReD50371.2020.9250 949

Citation: Kamal MM, Shanto MHI, Hossan MM, Hasnat MA, Sultana S, and Biswas M. (2022). A comprehensive review on the diabetic retinopathy, glaucoma and strabismus detection techniques based on machine learning and deep learning. Eur. J. Med. Health Sci., 4(2), 24-40. https://doi.org/10.34104/ejmhs.022.024040 @) () 